\title{
Accounting Chairpersons Compare Distance Learning Delivery Methodologies
}

Gary Saunders, (E-mail: saunderg@marshall.edu), Marshall University

\begin{abstract}
Distance learning delivery methodologies have evolved over the last 100, or so, years since the educational paradigm was formally used in American higher education. Several different approaches to distance learning, where the student is in a location remote from their instructor, have been used. During the decade of the 90s developments in technology offered new delivery vehicles for distance learning and terms like "interactive television" "E mail," and "Internet courses" have been added to the academic lexicon. Internet courses, where the interaction between faculty and student occurs primarily over the Internet, represent a substantial departure from the traditional learning model.
\end{abstract}

\section{Introduction}

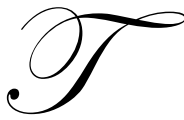

he growth in college and university offerings of distance learning courses over the Internet has been phenomenal and, as that growth accelerates there is little doubt that they will have an impact on the traditional university. However, one very important question is, will the new distance learning methodologies represent significant improvements over traditional pedagogy for educating students or just a lessening in the rigor of academic programs? Substantial research is needed to answer that question but faculty and administrators of universities will have a major influence on the answer.

This paper presents the opinions of accounting department chairpersons on some aspects of the relative level of control and quality of distance learning courses. An E mail questionnaire was delivered to 283 university accounting department chairpersons in the U S and 43 were completed and returned.

Two areas of the educational process for distance learning courses were explored, the level of control and the quality, relative to traditional classroom courses. Chairpersons believe that the level of control an instructor possesses with distance learning courses is substantially less than in traditional courses. Further, they have little confidence that the student receiving credit for a correspondence or an E course is actually completing the assignments..

When asked about the quality of distance learning courses chairpersons said that they were less rigorous than traditional courses. They also indicated that the performance of students in distance learning courses is worse than the performance of students in traditional courses. They would not, however, endorse the concept that students in distance learning courses received better grades for the same level of performance. Perhaps they believe that to endorse that concept would tend to undermine the integrity and objectivity of the grading process. On the other hand, maybe distance learning students are graded on the same basis as traditional campus students.

Distance learning delivery methodologies have evolved over the last 100, or so, years since the educational paradigm was formally used in American higher education. Several different approaches to distance learning, where the student is in a location remote from their instructor, have been used. In the late 1800s, Penn State University utilized the new "Rural Free Delivery" mail system to offer correspondence courses to students in remote locations [Banas \& Emory, 1998]. Although correspondence courses have been offered by a number of universities, the percentage of universities offering these courses is relatively small. Additionally, correspondence courses have never obtained the same degree of acceptance as traditional on-campus courses requiring a student's attendance and participation. During the past few decades universities have delivered instruction over long distances through 
interactive television (ITV) courses. While ITV courses have achieved limited acceptance, their use has not been widespread enough to challenge traditional, on-campus courses as the dominant educational methodology. In the decade of the 90 s electronic courses (E courses), utilizing the Internet, have become a reality. E courses, "the new kid on the block," have experienced phenomenal growth and they appear to be poised to challenge traditional, on-campus courses for students.

Typically distance learning courses require a student to finish a specific program of relatively independent study and successfully complete one, or more exams. These exams were, almost universally, proctored by an independent third party. Schools in the U.S. that have offered degrees completely by correspondence have typically not been mainstream colleges and universities but, have tended to offer paraprofessional degrees.

During the past few decades new technology allowed students to complete a course from a remote site with the faculty and students communicating, both verbally and visually, in real time using telephone line or a satellite uplink. This development of ITV technology represented another substantial improvement in the methodologies available to the academic process.

During the decade of the 90s developments in technology offered another new delivery vehicle for distance learning courses. Some jargon had to be added to describe the new environment so terms like "Internet courses," "chat rooms," "Email" and "E courses" were added to the academic lexicon. With the rapid spread of the Internet and Email, time and space ceased to be a problem as student and instructor could engage in the learning process in real time without the cumbersome television connections and paraphernalia. Could the need for the classroom setting be disappearing to be replaced by Email and chat rooms? Universities seemed to sense a source of previously untapped revenue, offering courses to anyone in the world who had a computer and an Internet connection.

E courses represent an even greater departure from the traditional learning model by allowing a student anywhere in the world to complete a course by using the Internet and Email. An important feature of the E course is that there is little incremental cost to the university or to the student for conducting a course over the Internet beyond the cost to subscribe to an Internet service provider. Universities have an initial investment in the development of an $\mathrm{E}$ course but the continuing cost of repeatedly offering the course is small compared to the potential revenue.

\section{Problems with Distance Learning Courses}

Some of the traditional controls available with correspondence courses are not as easily implemented with E courses. Proctoring of exams has been the norm with university correspondence courses and with ITV courses. A technical person is usually required at each ITV site to keep the equipment functioning so, proctoring is typically not a problem. However, with E courses proctoring becomes much more difficult.

One real advantage of $\mathrm{E}$ courses is its ability to provide educational opportunities to persons in extremely remote locations and this poses problems in locating certifiable proctors. Traditionally, proctors have been credentialed educators that were neutral with respect to the student. In population centers this type of proctor is not too difficult to locate but in the frozen tundra of Alaska or the sweltering outback of Australia, it may be impossible. In effect, when a university offers an E course with no required campus visits, it gives up virtually all of the traditional controls over the course and accepts on faith that the student receiving credit for the course is the same person who completes the assignments.

Perhaps to a greater degree than for correspondence courses, E courses are appropriate only for students who are highly motivated and capable of working independently with a minimum of personal instruction. Smith [Smith, IAEC 2000] discussed some of the advantages and disadvantages of E courses and pointed out, among others, the following disadvantages: 
- E courses are not for all students,

- Students must have the requisite computer skills to complete an E course,

- Face-to-face interaction is missing,

- Courses must be prepared in detail and approved before being offered and are rather unyielding to change,

- Communications must be very precise and many students and faculties are not proficient at communicating explicitly.

\section{Growth of $\mathbf{E}$ Courses}

Given the challenges that $\mathrm{E}$ courses present, colleges and universities would be expected to proceed cautiously and test carefully before implementing E courses and degree programs. Not so! The 1993 Peterson's College Guide listed 93 'cyberschools' and the 1997 Distance Learning Guide listed 762. That represents a phenomenal growth of more than 700 percent. Vasarhelyi and Graham [Vasarhelyi and Graham, 1997, p. 32] state that "In the last two years, the emergence of the Internet has opened the doors for a permanent revolution in the classroom and educational processes. . . About 55\% of America's 2,215 colleges and universities have courses available off site." There is little doubt that the number of colleges and universities offering E courses is growing rapidly.

In 1998 approximately 1,680 institutions were offering about 54,000 E courses with 1.6 million students enrolled. Projections call for 2.2 million students to be enrolled in E courses by 2002 and by 2005 it is expected to be a $\$ 46$ billion business (Carnevale, 2000). Not wanting to be seen as followers, universities are abandoning their traditionally conservative approach and are rushing headlong to cash in on the lottery. Their actions are reminiscent of the avarice appetite of the dot com investors in 1999 before the bubble burst in 2000.

As researchers speculate on the impact that $\mathrm{E}$ courses and programs will have on the traditional university, there are some important questions that need to be answered. For example, do newer delivery methodologies represent significant improvements over traditional pedagogy for educating students or just a lessening in the rigor of academic programs? How do these new delivery methods compare with the traditional classroom? Substantial research is needed to answer that question over a time frame of several years. In the shorter term, faculty and administrators of universities will have a major influence on whether these new delivery methods will be an improvement or a detriment to the educational process. They will play a vital role in crafting distance learning courses and programs for their respective universities and their attitudes should provide a glimpse of the future impact of new delivery methods on traditional university courses and degrees.

Accounting department chairpersons will help shape the future of distance learning courses and, in order to determine their opinions about distance learning courses and programs, an E mail questionnaire was developed and sent to 330 university accounting department chairpersons in the U. S. Forty-seven of the questionnaires were undeliverable because of errors in $\mathrm{E}$ mail addresses or because the person had left the institution. Of the 283 questionnaires that were apparently delivered, 43 were completed and returned yielding a response rate of $15.2 \%$. Statements in the questionnaire addressed three types of distance learning courses, correspondence, ITV, and E courses. Questionnaire statements related to two issues pertinent to distance learning: control of the educational process and quality of the learning experience. Both of these issues were addressed relative to the "traditional" learning environment in the classroom. No effort was made to slant either questions or response categories in a direction that might influence responses and no effort was made to detect any response bias from the question arrangement or the direction of the response categories. In the study the terms "Internet course" and "E course" were considered interchangeable.

Questionnaires were sent via E mail over the Internet and three different response modes were suggested. If respondents were concerned about anonymity, it was suggested that they either 1) print the questionnaire, complete it, and mail it to the author or, 2) click on an Internet address and complete a web page version. Both of these response methods would help insure anonymity. The third method of responding was to choose "reply" in their E mail program, complete the questionnaire, and click on "send." Responses began arriving within hours of the initial mailing. 


\section{Results}

Data indicated that the typical respondent was a chairperson of an accounting department in a public university with a total FTE enrollment between 5,001 and 10,000 students. The college of business had slightly more than 1,000 FTE students and about 200 of them were majoring in accounting, was accredited by the AACSB, and the accounting program was as likely as not to be accredited. The typical school offered an MBA and more than half offered a masters degree in Accounting.

\section{Control}

One potential problem with distance learning courses is that the level of control the instructor has over the integrity of the learning process would appear to be less in distance learning courses than in traditional courses. If that is true, distance learning models should be designed to overcome this weakness. Two statements related to the level of control that an instructor has in distance learning courses compared with traditional classroom courses. The first statement said "compared to traditional courses the level of control the instructor possesses with, correspondence courses is" less or more. The statement was repeated for ITV courses and E courses. Response percentages and categories are shown in the graph below.

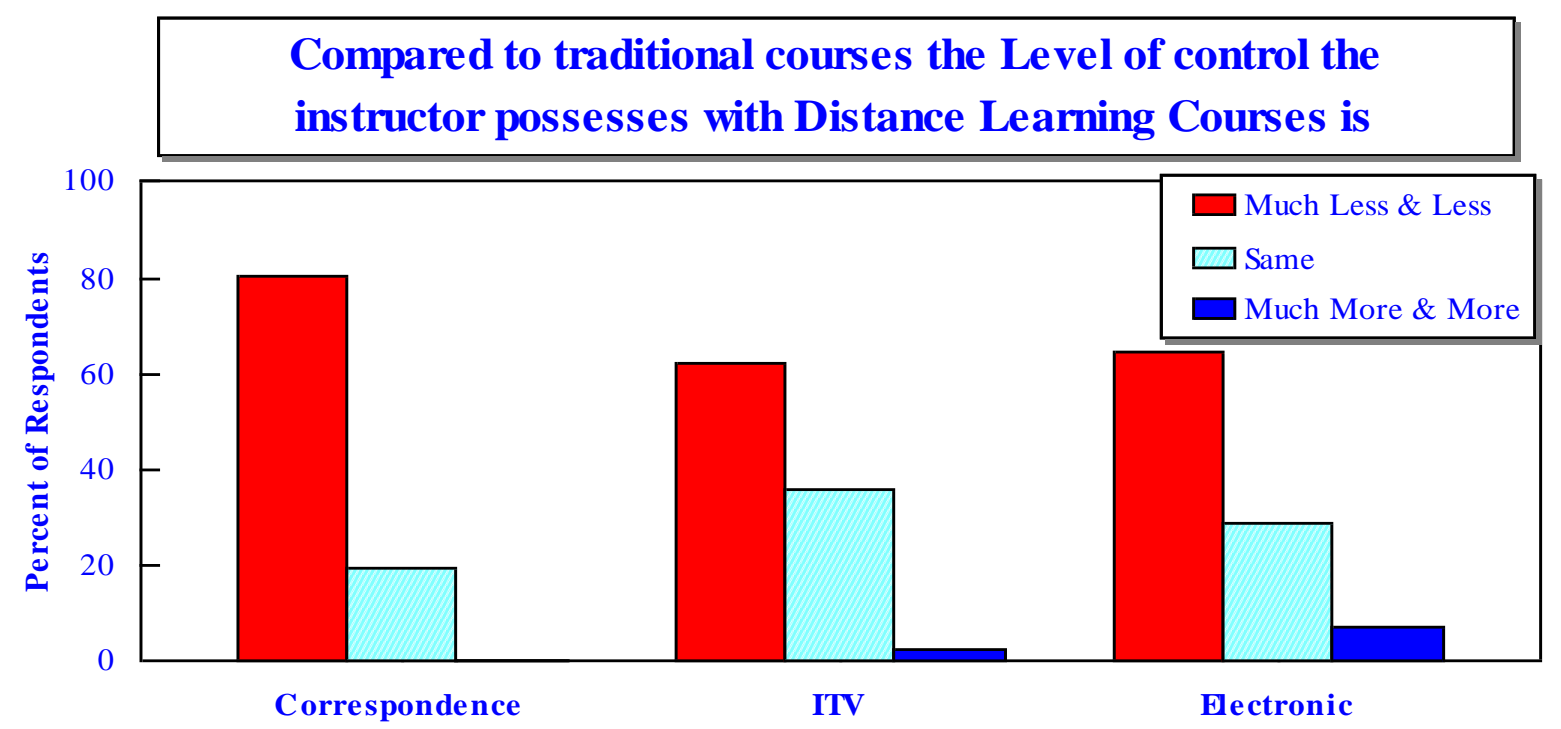

More than $80 \%$ of the accounting chairpersons responded that the level of control the instructor possesses with correspondence courses was less or much less than in traditional courses and over $34 \%$ believed it was much less. The remaining $19.5 \%$ felt that the level of control was about the same but no one believed it was more than in traditional courses. That overwhelming lack of confidence in the level of control available with correspondence courses suggests that a problem may have existed for years with correspondence. Experience indicates that many steps have been taken to control the problem.

Responding to the same question relative to ITV courses, no one indicated that the control was much less than in traditional courses but $61.9 \%$ indicated that it was less. Of the remaining $38.1 \%, 35.7 \%$ believed the control was about the same and $2.4 \%$ said it was more with ITV courses. Responses about E courses were similar with $64.3 \%$ believing that the control was much less or less and only $7.1 \%$ indicating that it was more. The other $28.6 \%$ thought it was about the same level of control. By wide margins, more than 80 to 1 for correspondence courses, 25 to 1 for ITV, and 9 to 1 for E courses respondents see the level of control with distance learning courses as being less than with traditional courses. 
Chairpersons believe that the level of control the instructor possesses with ITV and E courses is less than with traditional courses but by a smaller margin than for correspondence. Data indicate that they see the level of control to be the least with correspondence courses followed by E courses and ITV courses offering the most control of the three but still lower than traditional courses.

The concept of control includes a number of aspects of the education process and one of those is the level of assurance that the student receiving credit for the course is actually completing the course assignments. With a traditional course any assignment, such as homework, problems, or papers, that is not completed in class leaves room for doubt about the authorship of the work. Students work on assignments together, copy work, or purchase assignments and hand them in as their own work. In distance learning courses a majority, and in some instances all, of the assignments are completed outside of a classroom setting and the identification of the person actually completing the assignments becomes even more difficult. Some E courses do not even require a verified, objective proctor for exams, or even exams for that matter.

The second statement relating to control said "compared to traditional courses, faculty are less certain that the student is actually completing the assignments when they teach" and the delivery mode was given for each of the three distance learning methods. Responses are shown in the graph below.

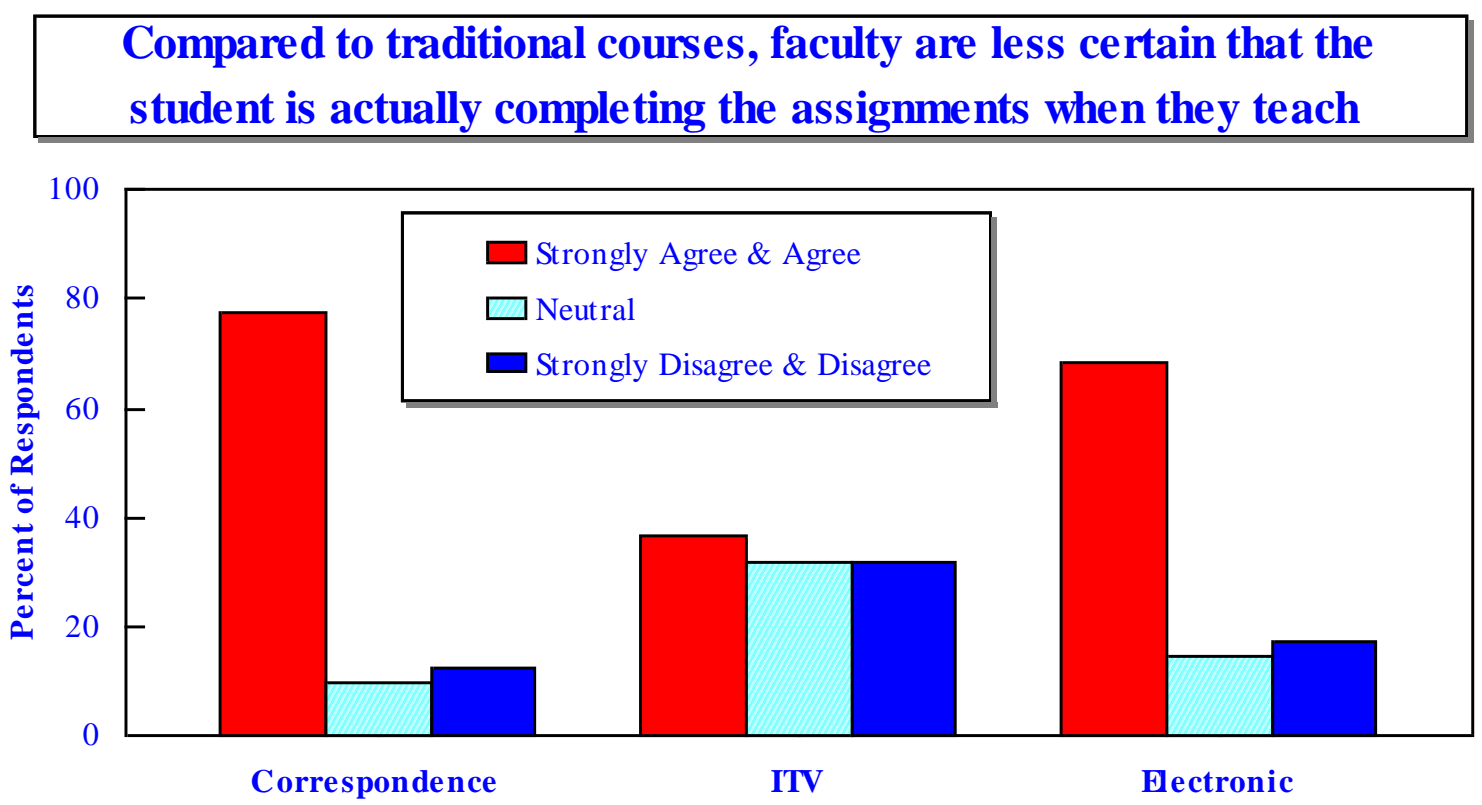

The level of uncertainty is greatest with correspondence with $77.5 \%$ of the chairpersons strongly agreeing or agreeing that faculty are less certain who is completing the assignments. Of that number one-third (27.5\%) strongly agreed. A relatively small number, $10 \%$, were neutral and the remaining $12.5 \%$ disagreed with the statement. E courses caused next highest level of concern with $68.3 \%$ strongly agreeing or agreeing (17.1\% strongly agreeing) that faculty were less certain about assignments. Seventeen percent disagreed and the remaining $14.6 \%$ were neutral. Respondents were almost evenly split on the issue with respect to ITV courses with $36.6 \%$ in agreement, $31.7 \%$ disagreeing and a similar amount, $31.7 \%$, neutral.

Apparently, accounting chairpersons have little confidence in who is actually completing assignments when students take correspondence or E courses. Probably because ITV courses allow the instructor to actually see the students in the course, they have more confidence that students are completing their own assignments in ITV courses than they do in either correspondence or E courses. 


\section{Quality}

Another issue with distance learning courses is the question of the relative quality of the courses compared with traditional courses. Anecdotal evidence suggests that distance learning courses may be of lower quality than traditional classroom courses. Three statements were included in the questionnaire to obtain attitudes relative to some facets of course quality. These statements addressed the relative rigor, student performance, and grading in distance learning courses compared to traditional courses.

The first statement said that "compared to traditional courses, correspondence courses tend to be" less or more rigorous. The statement was repeated for ITV and $\mathrm{E}$ courses and responses percentages and response categories are shown in the graph below. Sixty-five percent of the chairs believed that correspondence courses were either much less rigorous or less rigorous than traditional classroom courses.

Confidence in the rigor of ITV courses less negative than for correspondence courses but, it was still negative with 35\% of the chairs indicating that they were much less or less rigorous than traditional courses and no respondent indicating that they were more rigorous. More than half (65\%) thought they were about the same. About the same percentage, $33.4 \%$, believed that $\mathrm{E}$ courses were less rigorous but $12.8 \%$ believed they were more rigorous than traditional courses.

\section{Compared to traditional courses, Distance Learning Courses tend to be:}

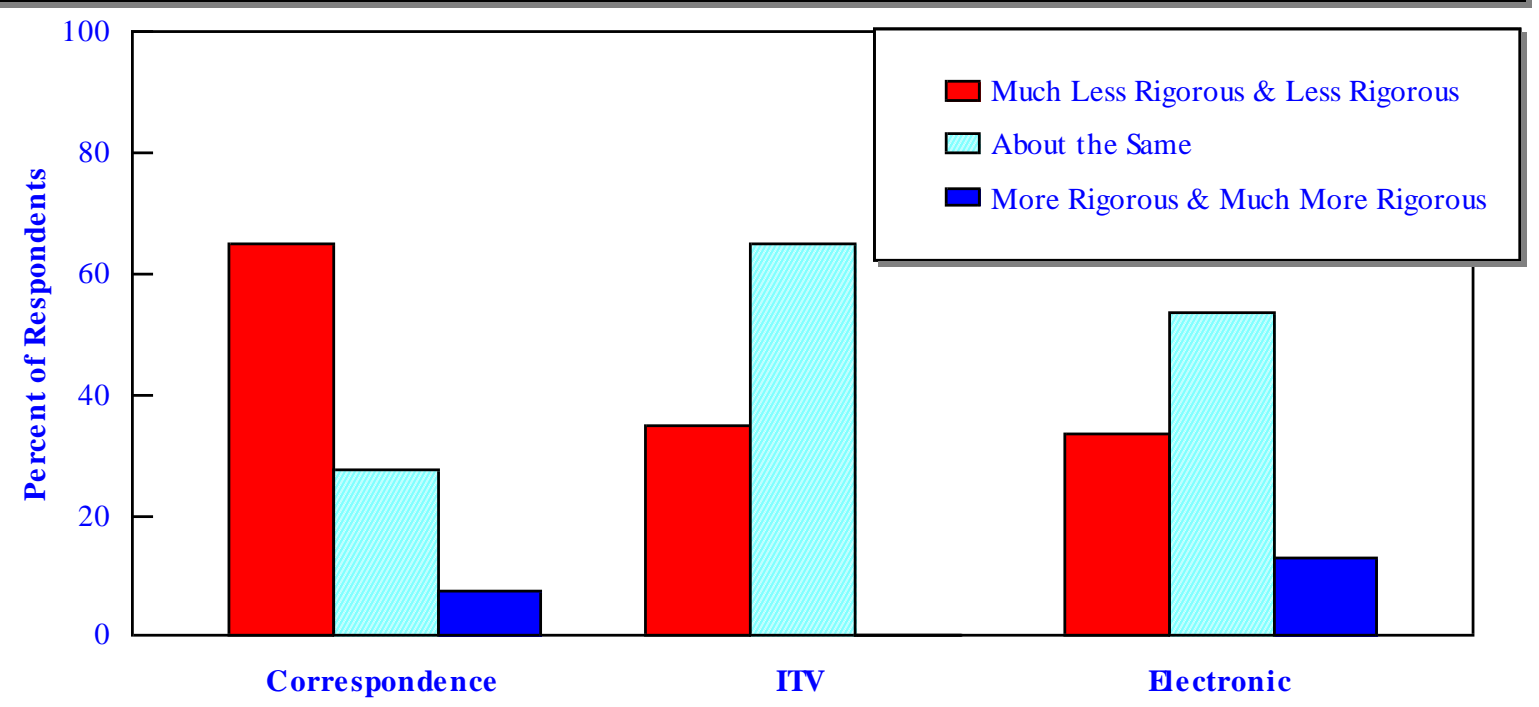

Overall, accounting chairpersons do not believe that distance learning courses are as rigorous as traditional courses. Of the three, correspondence courses received the largest vote of no confidence with $65 \%$ indicating they were less rigorous. Opinions about ITV and E courses were somewhat less negative but respondents still believed they were less rigorous.

A second aspect of quality is the relative performance of students in distance learning courses. One statement said that "compared to students in traditional courses, students in correspondence courses tend to perform" better or worse than in traditional courses and the statement was repeated for ITV and E courses. Response categories were "much better," "better," "about the same," "worse," and "much worse." Response percentages for the three types of distance learning courses are shown in the graph below. 


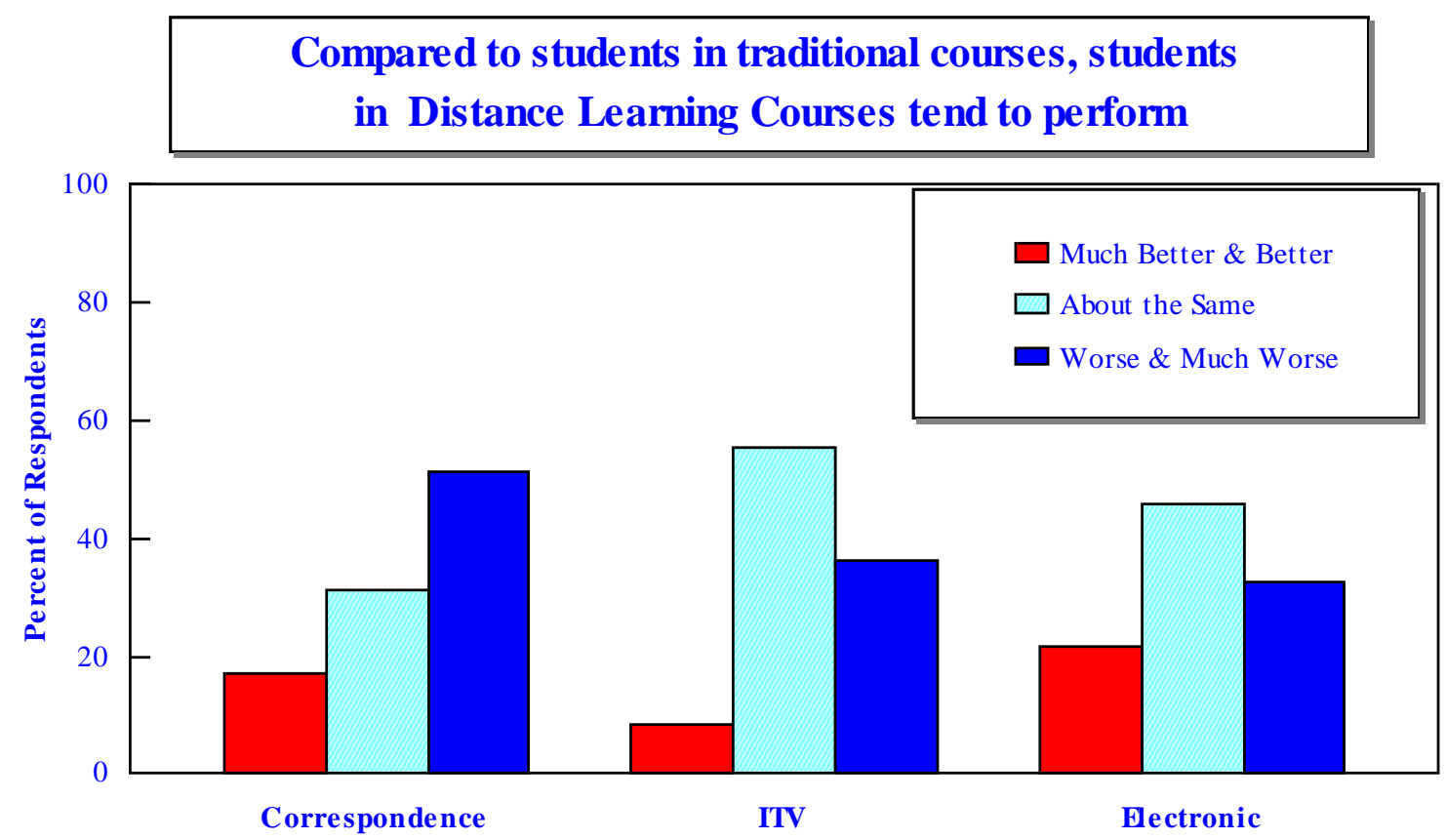

Only $17.1 \%$ said that students in correspondence courses performed better than students in traditional courses while $51.5 \%$ said they performed worse or much worse. By a 3 to 1 margin accounting chairpersons believe that students in correspondence courses perform worse than students in traditional courses.

Although the absolute percentage was less, respondents indicated by a greater margin, more than 4 to 1 , that the performance of students in ITV courses was worse than in traditional courses. Slightly more than $36 \%$ indicated that students in ITV courses performed worse and only $8.3 \%$ said they performed better. More than half of the respondents, 55.6\%, believed that ITV students performed about the same, up from $31.4 \%$ for correspondence courses. This difference may reflect a greater familiarity with ITV courses and, therefore, a little more confidence in the students. Still, $36.1 \%$ believed that they performed worse compared with only $8.3 \%$ who believed they performed better.

When responding to the same statement about E courses $21.6 \%$ said that students performed better and $32.4 \%$ said they performed worse. Surprisingly, a larger percentage of the chairs believe that students in E courses perform better than traditional students than the percentage that believed ITV students performed better. That is surprising because $68.3 \%$ said that they are less certain that the student is actually completing the assignment in E courses compared with $36.6 \%$ for ITV courses.

The last aspect of quality that was investigated related to grading in the course. One statement said "compared to students in traditional courses, students in correspondence courses tend to receive better grades for the same level of performance." As before, the statement was repeated for ITV and E courses. Response percentages are shown in the graph below. 


\section{Compared to students in traditional courses, students in Distance Learning Courses tend to receive better grades for the same level of performance}

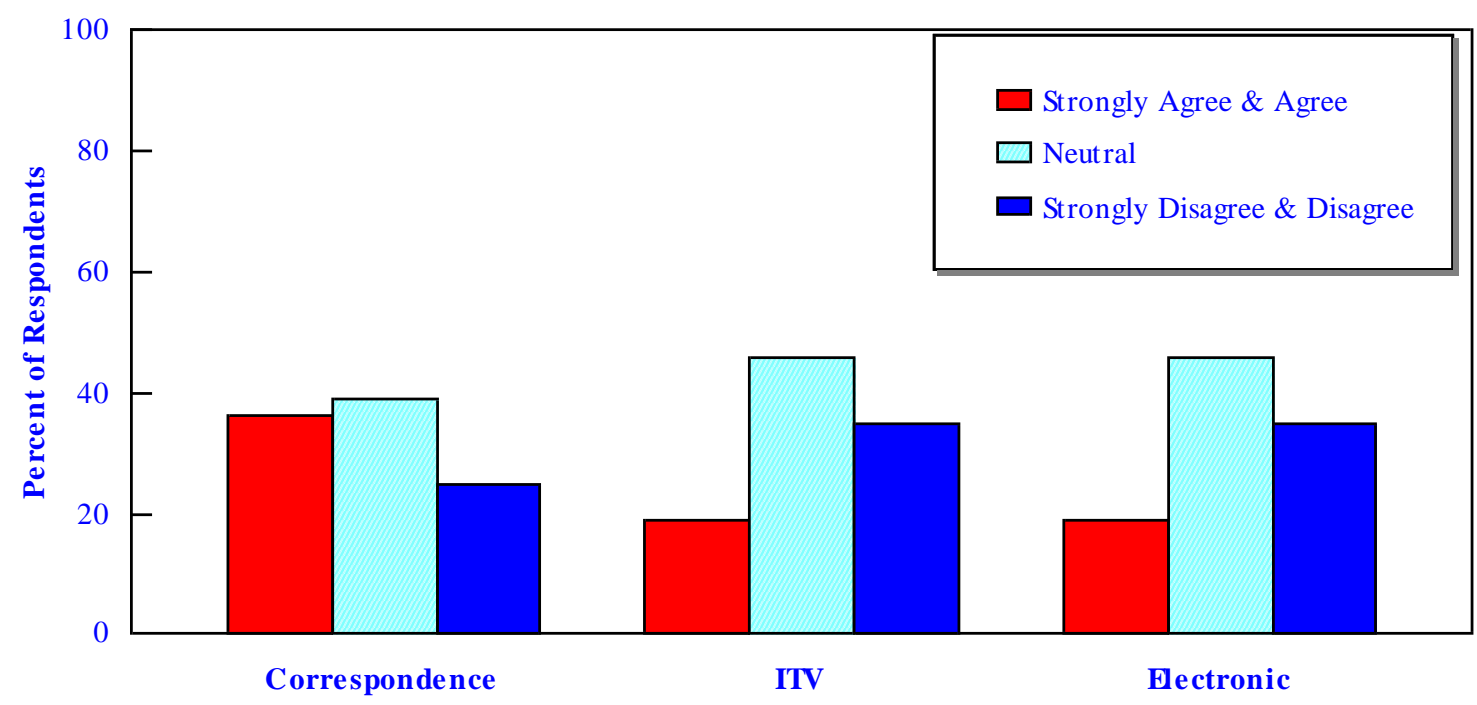

Accounting chairs tended to agree with the statement for correspondence courses but, they disagreed with it for ITV and E courses. Slightly more than 36\% agreed, with 5.6\% strongly agreeing, that students in correspondence courses receive better grades than students in traditional courses for the same level of performance. Twenty-five percent of the respondents disagreed with the statement and 38.9\% were neutral. For both ITV and E courses only $18.9 \%$ of the chairs agreed with the statement and $35.1 \%$ disagreed.

Responses to these statements may reflect a reluctance to endorse the concept that the grading criteria might be different for the different types of courses, i.e., traditional and distance learning. Perhaps they made an exception for correspondence courses because they consider them to be "old" technology or because they have little personal experience with them. Correspondence courses are typically administered by a separate "extension" unit while ITV and $\mathrm{E}$ courses are usually administered by the academic unit.

\section{Summary}

Overall, accounting chairpersons are not very supportive of distance learning courses. More than $80 \%$ believe that the level of control that an instructor possesses with correspondence curses is substantially less that with traditional courses. Uncertainty over who is actually completing the assignments in correspondence courses exists with $77.5 \%$ saying they are less certain than with traditional courses. The quality of correspondence courses is also questioned as $65 \%$ of the chairs believed that correspondence courses are less rigorous and $51.5 \%$ said students performed worse in correspondence courses than in traditional courses. Chairpersons appear to be suggesting that the days of the correspondence courses are past. This may be from a real distrust of the courses and how they are administered or, it might be that they see the technology as "outdated" and endorse replacing it with the Internet.

Respondents were less critical of ITV courses. Although $61.9 \%$ believed that the level of control was less for ITV courses, responses were about evenly split about the level of certainty that the student receiving credit for the course is actually completing the assignments. With respect to quality, 35\% indicated that ITV courses were less rigorous than traditional courses and no one felt they were more rigorous. By a 4 to 1 margin respondents said that students in ITV courses performed worse than in traditional courses. As with correspondence courses they did not endorse the idea that students in ITV courses received better grades for the same level of performance. 
Accounting chairs have some of the same concerns about E courses that they have with correspondence courses. More than $64 \%$ said that the level of control was less, compared with $80.5 \%$ for correspondence, for E courses than for traditional courses. Also, $68.3 \%$ felt they were less certain that the student was actually completing the assignments than with traditional courses. Apparently, chairs feel that E courses and correspondence courses share some of the same control problems. E courses are judged better than correspondence courses on the quality factors. Although E courses are considered less rigorous than traditional courses, the percentage of respondents endorsing that concept is about half of that for correspondence courses. Similarly, responses about relative student performance were negative for $\mathrm{E}$ courses but not as negative as for correspondence courses.

\section{References}

1. _L "New AFT Report Proposes Standards for Online Programs," Black Issues in Higher Education Vol. 17, Issue 5, February 1, 2001, p. 43.

2. Banas, Edward J. and Emory, W. Frances, History and Issues of Distance Learning, Public Administration Quarterly, p. 365-383, v. 22, issue 3.

3. Carnevale, Dan, “Turning Traditional Courses Into Distance Education," Chronicle of Higher Education, Vol 46, Issue 48, August 4, 2000, p A37-9.

4. Carr, Sarah, "A University Moves to Require Distance Courses," Chronicle of Higher Education, Vol. 47, Issue 8, October 20, 2000, p A48.

5. Gaskin, James E. \& Calera, Robert E., "Virtual Learning Struggling to Make the Grade," Inter@active Week, Vol 7, Issue 4, August 28, 2000, p 28-9.

6. Hagen, A. \& Omolayole, O., "The Impact of Technology Mediated Distance Learning on American Business Colleges: an Empirical Investigation," Proceedings of the OOICTL-Business 2000 International Conference, p. 143-6, September, 2000. Shreveport, LA.

7. Hereford, Lady, "Virtually No Consistency in Online College Courses," Community College Week, Vol. 12, Issue 15, March 6, 2000, p 8-9.

8. Oblinger, Diana \& Kidwell, Jill, “Distance Learning Are We Being Realistic?” Educause Review, Vol. 35, Issue 3, May/June 2000, p 30-37.

9. Oppermann, O., "E-mail Surveys - Potentials and Pitfalls," Marketing Research, 7(3), 1995, p 29-33.

10. Roach, Ronald, "The Army Marches Into Online Learning," Black Issues in Higher Education Vol. 17, Issue 24, January 18, 2001, p. 32-3.

11. Smith, W., "The Advantages and Disadvantages of Online Delivery of Accounting Courses: Pitfalls to Avoid," Presented at the Fiftieth International Economics Conference, October, 2000. Charleston, SC.

12. Svetcov, Danielle, “The Virtual Classroom vs the Real One," Forbes, Vol. 166, Issue 7, p. 50-52, September $11,2000$.

13. Vasarhelyi, M. A., \& Graham, L., "Cybersmart: Education and the Internet," Management Accounting, Aug., 1997, p 32-36. 
Notes 